\title{
Long-term Impact on the Marine Environment
}

\author{
-Simulation of the Marine Dispersion of Released \\ Radionuclides from Fukushima-Daiichi Nuclear Power \\ Plant and Estimation of Internal Dose from Marine \\ Products-
}

\author{
Japan Atomic Energy Agency, Masanao Nakano
}

\begin{abstract}
As a result of the accident at Fukushima Daiichi Nuclear Power Plant caused by the 2011 Off the Pacific Coast of Tohoku Earthquake and tsunami on March 11, radioactive materials were released into the environment. A global scale calculation of the long-term diffusion of radioactive materials in ocean using long-term assessment model for radioactivity in the oceans (LAMER), which is a calculation code developed by Japan Atomic Energy Agency, was conducted to estimate their concentration in seawater and the exposure dose caused by seafood ingestion.

When we postulate that $8.45 \mathrm{PBq}$ of ${ }^{137} \mathrm{Cs}$ has been released, the calculation of the ${ }^{137} \mathrm{Cs}$ concentration in seawater after April 2012 would be a maximum of $\sim 23$ $\mathrm{Bq} / \mathrm{m}^{3}$, which is $\sim 14$ times more than the concentration originated from atmospheric nuclear tests before the accident. The highest concentration continued to decrease after that point of time, and it will be of the same level as the concentration originated from the nuclear tests by 2023 . Moreover, internal exposure from ${ }^{131} \mathrm{I},{ }^{134} \mathrm{Cs}$, and ${ }^{137} \mathrm{Cs}$ caused by seafood ingestion was calculated to be a maximum of $1.8 \mu \mathrm{Sv} / \mathrm{y}$, which is approximately equal to the past yearly dose derived from the atmospheric nuclear tests.
\end{abstract}

\section{Introduction}

Fukushima Daiichi Nuclear Power Plant of Tokyo Electric Power Company Holdings, Inc. (TEPCO) suffered from a major tsunami caused by the 2011 Off the Pacific Coast of Tohoku Earthquake on March 11. This was followed by the release of radioactive materials into the environment, causing concerns about their effects on the environment.

Although the accident is yet to be resolved, this study will present the overview of the state of ocean monitoring, estimation of the amount of release into the ocean, and the state of marine diffusion simulation.

In particular, regarding the prediction of long-term environmental impacts in the future,

DOI : 10.15669/fukushimainsights.Vol.1.96

(C) 2021 Atomic Energy Society of Japan. All rights reserved.

Originally published in Journal of the Atomic Energy Society of Japan (ISSN 1882-2606), Vol. 53, No. 8, p. 559-563 (2011)

in Japanese. (Japanese version accepted: June 13, 2011) 
we conducted the global scale year-to-year marine diffusion calculation as well as estimated the concentration of radioactivity in seawater and the exposure dose caused by seafood ingestion using long-term assessment model for radioactivity in the oceans (LAMER) ${ }^{1}$, which is a calculation code developed by Japan Atomic Energy Agency (JAEA).

\section{Implementation Status of Sea Monitoring}

\section{Sea Monitoring}

The Ministry of Education, Culture, Sports, Science, and Technology and TEPCO have been sampling and analyzing seawater since March 21, 2011. TEPCO's facility has contributed to the detection of the following nuclides: ${ }^{58} \mathrm{Co},{ }^{99 \mathrm{~m}} \mathrm{Tc},{ }^{89} \mathrm{Sr},{ }^{90} \mathrm{Sr},{ }^{131} \mathrm{I},{ }^{132} \mathrm{I},{ }^{134} \mathrm{Cs},{ }^{136} \mathrm{Cs},{ }^{137} \mathrm{Cs},{ }^{140} \mathrm{Ba}$, and ${ }^{140} \mathrm{La}$. Among them, the concentrations of ${ }^{131} \mathrm{I},{ }^{134} \mathrm{Cs}$, and ${ }^{137} \mathrm{Cs}$ were relatively higher than the concentration limit provided by the dose notification in Table 1. Table 1 shows the highest concentration of radioactive materials in seawater obtained until the end of May. The concentration exhibited a tendency to decrease as the distance from the power plant increased. The ${ }^{137} \mathrm{Cs} /{ }^{131} \mathrm{I}$ ratio of the seawater concentration decreased further it went from the power plant. As the distribution coefficients at the coast (the ratio of concentration in seabed soil to that of seawater in equilibrium state) are 4,000 and 70 for cesium and iodine respectively, Cesium is selectively transferred to the seabed soil compared to iodine. Further, the ${ }^{137} \mathrm{Cs} /{ }^{131} \mathrm{I}$ ratio in the seawater concentration was increasing daily, resulting in the physical decay of ${ }^{131} \mathrm{I}$, whose half-life is eight days, thereby decreasing its concentration.

Table 1 Highest concentration of radioactive materials in seawater

\begin{tabular}{|c|c|c|c|}
\hline & & & Unit: $\mathrm{Bq} / \mathrm{cm}$ \\
\hline Location & ${ }^{131} \mathrm{I}$ & ${ }^{134} \mathrm{Cs}$ & ${ }^{137} \mathrm{Cs}$ \\
\hline $\begin{array}{l}\text { Near the Power Plant } \\
\text { (Excluding the extreme } \\
\text { proximity) }\end{array}$ & $\begin{array}{l}\sim 180 \text { (Near 1F South Water } \\
\text { Canal, March 30) }\end{array}$ & $\begin{array}{l}\sim 67 \text { ( North of Water Canal } \\
\text { of } 1 \text { F } 5-6, \text { April 7) }\end{array}$ & $\begin{array}{l}\sim 68 \text { (North of Water Canal } \\
\text { of } 1 \text { F } 5-6, \text { April } 7 \text { ) }\end{array}$ \\
\hline Coastal Area & $\begin{array}{l}\text { 3.8 (Near 2F North Water } \\
\text { Canal, March 28) }\end{array}$ & $\begin{array}{l}\sim 1.4 \text { (2F Near Iwazawa } \\
\text { Beach, April 5) }\end{array}$ & $\begin{array}{l}\sim 1.4 \text { (2F Near Iwazawa } \\
\text { Beach, April 5) }\end{array}$ \\
\hline $15 \mathrm{~km}$ off the Coast & $\begin{array}{l}\sim 0.18 \text { (15 km off Iwazawa } \\
\text { Beach, April 5) }\end{array}$ & $\begin{array}{l}\sim 0.31 \text { (15 km off Iwazawa } \\
\text { Beach, April 5) }\end{array}$ & $\begin{array}{l}\sim 0.32 \text { (15 km off Iwazawa } \\
\text { Beach, April 5) }\end{array}$ \\
\hline $30 \mathrm{~km}$ off the Coast & $\sim 0.161$ (Plant 4, April 15) & $\sim 0.166$ (Plant 4, April 15) & $\begin{array}{l}\sim 0.186 \text { (Location 4, April } \\
15 \text { ) }\end{array}$ \\
\hline $\begin{array}{l}\text { Concentration Limit in } \\
\text { Water defined by the } \\
\text { Notification }\end{array}$ & 0.04 & 0.06 & 0.09 \\
\hline $\begin{array}{l}\text { Concentration before the } \\
\text { Accident }\end{array}$ & Not detected & Not detected & $\begin{array}{l}0.0000017 \text { (2009 Average, } \\
\text { Off the coast of Fukushima) }\end{array}$ \\
\hline
\end{tabular}

\section{Marine Dispersion Simulation}

As of the end of May, the Ministry of Education, Culture, Sports, Science, and Technology (Japan Agency for Marine-Earth Science and Technology) and a French research group conducted dispersion simulation focused on the coastal area and published the results of their calculations on the Internet. Although there is a difference in the behavior at the initial stage of release, both are expected to disperse while moving in northeast to eastward direction. 


\section{Estimation of the Amount of Release into the Ocean}

\section{(1) Deposition from atmospheric release to sea surface}

After being struck by the tsunami, radioactive materials were released into the atmosphere from the power plant via venting and hydrogen explosion. According to the data released by Nuclear and Industrial Safety Agency (NISA) of the Ministry of Economy, Trade and Industry on June 6, the amounts released to the atmosphere between March 11 and March 16 were 160,18 , and $15 \mathrm{PBq}$ for ${ }^{131} \mathrm{I},{ }^{134} \mathrm{Cs}$, and ${ }^{137} \mathrm{Cs}$, respectively. Moreover, according to the distribution map of the estimates of intrathyroidal exposure dose by System for Prediction of Environmental Emergency Dose Information (SPEEDI) published on March 23 by Nuclear Safety Commission, the ratio of distribution of dose to the seaward direction and landward direction was 45:55. From these data, we inferred that 50\% of the total released amount to the atmosphere moved to the ocean and 80,9 , and $7.5 \mathrm{PBq}$ of ${ }^{131} \mathrm{I},{ }^{134} \mathrm{Cs}$ and ${ }^{137} \mathrm{Cs}$, respectively, deposited on the sea surface. Although quantitatively small, the release into the atmosphere continued even after March 16, albeit in small amounts.

\section{(2) Highly Contaminated Water}

According to the NISA report on April 2, 2011, it was found that highly contaminated water that exceeds $1 \mathrm{~Sv} / \mathrm{h}$ in the pit near the water intake of Unit 2 on the same day and it was being released into the sea. Moreover, extremely high concentrations of the inflow water to the Unit 2 screen were collected that day: $5.4 \times 10^{6}, 1.8 \times 10^{6}$, and $1.8 \times 10^{6} \mathrm{~Bq} / \mathrm{cm}^{3}$ for ${ }^{131} \mathrm{I},{ }^{134} \mathrm{Cs}$, and ${ }^{137} \mathrm{Cs}$, respectively. According to the TEPCO report on April 21, it was estimated that the release during the five days from April 1 to April 6 were 2.8, 0.94, and $0.94 \mathrm{PBq}$ for ${ }^{131} \mathrm{I},{ }^{134} \mathrm{Cs}$, and ${ }^{137} \mathrm{Cs}$, respectively.

Furthermore, according to the TEPCO report on May 21, $250 \mathrm{~m}^{3}$ of high-concentration water containing $3.4 \times 10^{3}, 3.7 \times 10^{4}$, and $3.9 \times 10^{4} \mathrm{~Bq} / \mathrm{cm}^{3}$ of ${ }^{131} \mathrm{I},{ }^{134} \mathrm{Cs}$, and ${ }^{137} \mathrm{Cs}$, respectively, was released from Unit 3 between May 11 and May 12. The released amount of ${ }^{131} \mathrm{I},{ }^{134} \mathrm{Cs}$, and ${ }^{137} \mathrm{Cs}$ was $0.85 \mathrm{TBq}, 9.3$, and $9.8 \mathrm{TBq}$, respectively.

Meanwhile, judging from the fact that around $100 \mathrm{~Bq} / \mathrm{cm}^{3}$ of ${ }^{131} \mathrm{I}$ had been continuously detected from the seawater collected near the water discharge port after March 25, there was a possibility that another highly contaminated water had been leaking into the sea during late March. Note that the concentration in the seawater continued to decrease after April 7 and April 8. By April 9, the concentrations of ${ }^{131} \mathrm{I}$ and ${ }^{137} \mathrm{Cs}$ were $\sim 10 \mathrm{~Bq} / \mathrm{cm}^{3}$. By the end of April, ${ }^{137} \mathrm{Cs}$ was $\sim 0.1 \mathrm{~Bq} / \mathrm{cm}^{3}$. However, there was no significant decrease in ${ }^{137} \mathrm{Cs}$ concentration in May.

(3) Low-Level Retained Water, etc.

According to the reports by NISA, between April 4 and April 10, 9,070 tons of low-level retained water was released from the integrated waste processing facility and $\sim 1,323$ tons of low-level ground water was released from the sub drains of Unit 5 and Unit 6 . The total released amount of low-level retained water was estimated to be $150 \mathrm{GBq}$. Compared to sections II-3 (1) and (2), it was $\sim 1 / 670,000$.

\section{Total Amount of Release into the Ocean after this Accident}

As of the end of May, there are three routes for the release of ${ }^{131} \mathrm{I},{ }^{134} \mathrm{Cs}$, and ${ }^{137} \mathrm{Cs}$ into the ocean as a result of this accident, which are listed on sections II-3 (1)-(3). The total of these is shown in Table 2. 
Table 2 Estimated amount of release into the ocean (As of June 6, 2011)

\begin{tabular}{lccc} 
& & & Unit: PBq \\
\hline Route & ${ }^{131} \mathrm{I}$ & ${ }^{134} \mathrm{Cs}$ & \\
\hline $\begin{array}{l}\text { (1) Released into atmosphere and deposited on sea surface. } \\
\text { (March 11-16) }\end{array}$ & 80 & 9.0 & 0.94 \\
(May 10-11) & 2.8 & 0.94 & 0.0098 \\
(2) High concentration contaminated water. (April 1-6) & 0.00085 & 0.0093 & 0.000042 \\
(3) Low level retained water, etc. (April 4-10) & 0.000066 & 0.000042 & 8.45 \\
\hline Total & 82.8 & 9.95 & \\
\hline
\end{tabular}

\section{Long-Term Marine Dispersion Simulation}

\section{Calculation Method}

\section{(1) Calculation Model}

The purpose of this prediction is to grasp the comprehensive view of the global scale diffusion in seawater after more than one year. As its purpose is not to predict the dispersion in the coastal area, LAMER wide-area model was used. The calculation conditions are listed in Table 3. The annual average of three-dimensional velocity field was obtained using a diagnostic method that uses ocean general circulation model (a method of restoring observation values of water temperature and salinity to successively calculated values). In the calculation of the concentration of radioactive materials in sea water, a particle diffusion model (a large number (150,000 particles for this calculation) of particles hypothetically having radioactive substances are advected in the flow velocity field and are diffused by random numbers) was used. Based on the result of seawater monitoring in II-1, the target nuclides were ${ }^{131} \mathrm{I},{ }^{134} \mathrm{Cs}$, and ${ }^{137} \mathrm{Cs}$.

Table 3 Calculation conditions for LAMER wide-area model

\begin{tabular}{|c|c|c|}
\hline Model & Item & Condition \\
\hline \multirow{2}{*}{$\begin{array}{l}\text { Ocean General } \\
\text { Circulation Model }\end{array}$} & Grid size & $2^{\circ}$ on latitude and longitude direction; 15 layers vertically. \\
\hline & $\begin{array}{l}\text { Water temperature/salinity } \\
\text { content/wind stress }\end{array}$ & Annual averaged data. \\
\hline \multirow{5}{*}{$\begin{array}{l}\text { Particle Diffusion } \\
\text { Model }^{1)}\end{array}$} & Surface mixed layer & $100-300 \mathrm{~m}$ depending on the latitude. \\
\hline & & $\left(200 \mathrm{~m}\right.$ at $\left.40^{\circ} \mathrm{N}\right)$ \\
\hline & Horizontal diffusion coefficient & $1.3 \times 10^{4} \mathrm{~m}^{2} / \mathrm{s}$ \\
\hline & Vertical diffusion coefficient & $3 \times 10^{-5} \mathrm{~m}^{2} / \mathrm{s}$ \\
\hline & Others & $\begin{array}{l}\text { Sedimentation on seabed, re-flotation from the seabed, and } \\
\text { adsorption/desorption are not considered. }\end{array}$ \\
\hline Overall Model & $\begin{array}{l}\text { Verification of validity using } \\
\text { atmospheric nuclear test data. }\end{array}$ & $\begin{array}{l}\text { In the case of }{ }^{137} \mathrm{Cs}, 82 \% \text { and } 93 \% \text { of calculated values } \\
\text { were included within } 1 / 2-2 \text { times and } 1 / 5-5 \text { times of the } \\
\text { observed values, respectively. Thus, when the calculated } \\
\text { value is multiplied by the safety margin (twice), } 90 \% \text { of the } \\
\text { observed value will be included within the calculated value. }\end{array}$ \\
\hline
\end{tabular}


In the coastal areas, cesium has a slightly larger distribution coefficient than in the ocean. Iodine and cesium dissolve relatively easily in seawater compared to heavy metal elements ${ }^{2}$. Therefore, scavenging process (process where radioactive materials in seawater adhere to suspended particles and are carried to deep sea due to gravity) and other processes were not considered. In the coastal areas, cesium may deposit and its concentration in seawater may increase in the future owing to re-suspension and dissolution. For this calculation, ${ }^{137} \mathrm{Cs}$, which is an artificial radioactive nuclide and has a long half-life, was chosen as the representative nuclide. The calculation timescale was set to 30 years because it represents the half-life of ${ }^{137} \mathrm{Cs}$. The concentrations of ${ }^{131} \mathrm{I}$ and ${ }^{134} \mathrm{Cs}$ in seawater were adjusted by considering their released amounts and physical decay. The details of the diffusion model are given in a previous report ${ }^{1)}$.

\section{(2) Amount Input into the 0cean}

From the results of the estimation of the amount of release into the ocean in section II-3, it was assumed that $82.8,9.95$, and $8.45 \mathrm{PBq}$ of ${ }^{131} \mathrm{I},{ }^{134} \mathrm{Cs}$ and ${ }^{137} \mathrm{Cs}$, respectively, were released to the ocean at once on April 1, 2011 off the coast of Fukushima Daiichi Nuclear Power Plant and used for the calculation. This ${ }^{137} \mathrm{Cs}$ input corresponds to $\sim 0.9 \%$ of ${ }^{137} \mathrm{Cs}$ that released onto the earth by the atmospheric nuclear tests until now $(948 \mathrm{PBq})^{4)}$.

In the real atmospheric route, the deposition on the sea surface occurs after the transportation to the Pacific by the atmosphere. In that case, the diffusion speed is considered to be faster than the result of this calculation. The horizontal distribution of the amount of descent from the atmosphere was not considered at this stage, and all the radioactive materials from the atmosphere were assumed to deposit on the place of direct input on the sea and treated as contaminated water.

\section{(3) Calculation of Internal Exposure Dose Caused by Seafood Ingestion}

Table 4 shows the concentration factor, ingestion amount and effective dose coefficient that are necessary for calculating the internal exposure dose caused by seafood ingestion.

Moreover, the seawater concentration of the part with the highest concentration in the ocean surface layer discussed later was used as the seawater concentration. The calculation of the concentration and dose of the period less than one year after the release was not considered because this model uses annual average field.

Table 4 Concentration factor, ingestion amount, and effective dose coefficient

\begin{tabular}{lcccc} 
& \multicolumn{2}{c}{ Daily Consumption $(\mathrm{g} / \mathrm{d})^{5)}$} & \multicolumn{2}{c}{ Concentration Factor $\left(\mathrm{Bq} / \mathrm{kg}\right.$ Fresh per Bq/kg Water ${ }^{2)}$} \\
\cline { 3 - 5 } & & ${ }^{131} \mathrm{I}$ & ${ }^{134} \mathrm{Cs}$ & ${ }^{137} \mathrm{Cs}$ \\
\hline Fish & 64 & 9 & 100 & 100 \\
Crustacean & 5.4 & 3 & 50 & 50 \\
Cephalopod & 5.5 & $-(3)$ & 9 & 9 \\
Shellfish & 3.5 & 10 & 60 & 60 \\
Seaweed & 10 & 10000 & 50 & 50 \\
\hline Effective Dose Coefficient $(\mathrm{Sv} / \mathrm{Bq})$ & & $2.2 \mathrm{E}-08$ & $1.9 \mathrm{E}-08$ & $1.3 \mathrm{E}-08$ \\
\hline
\end{tabular}

\section{Calculation Results and Discussion}

(1) Concentration Distribution in Seawater

Figure 1 shows the concentration distribution of ${ }^{137} \mathrm{Cs}$ for 30 years in the surface layer of 

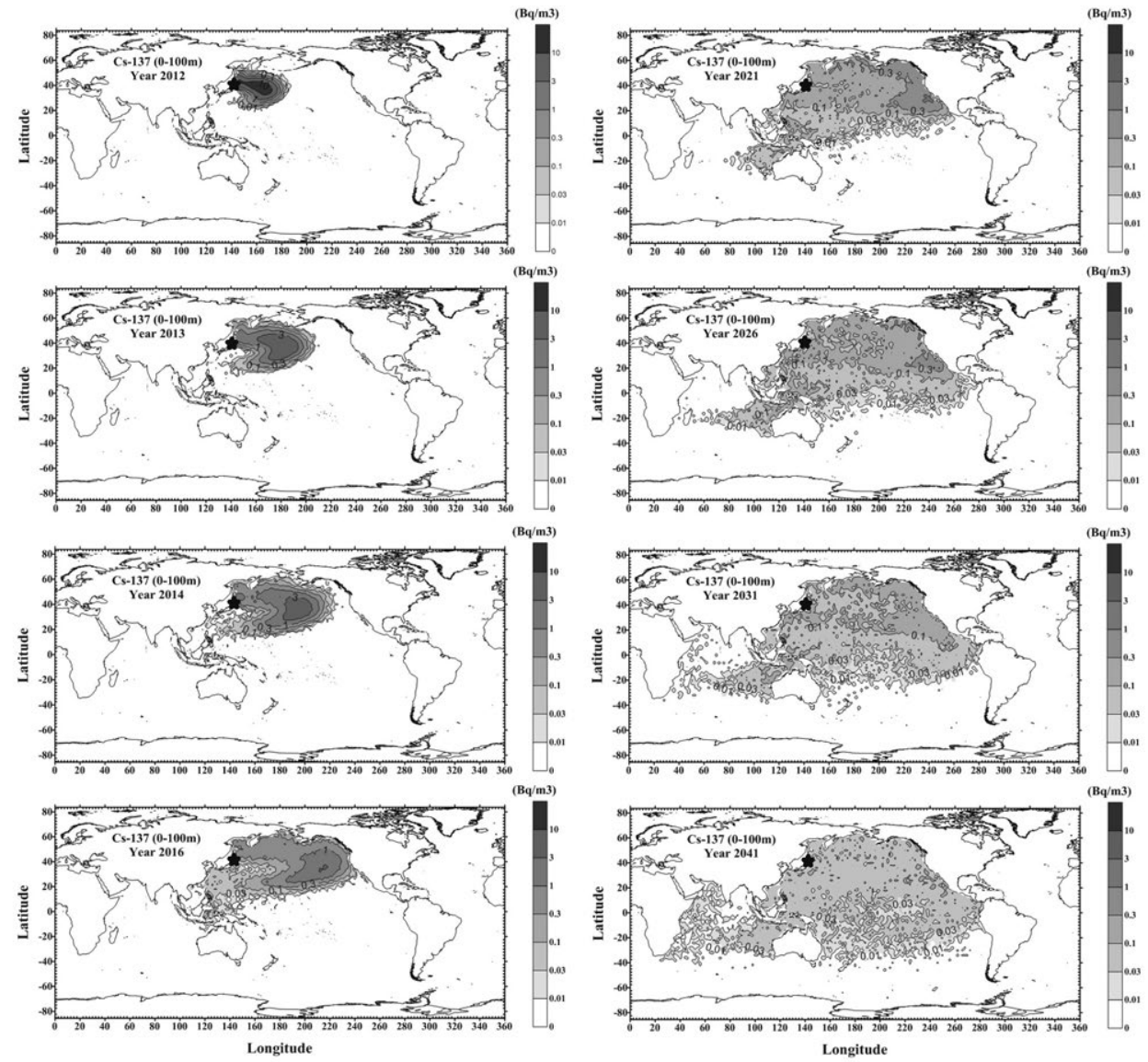

Figure 1 Concentration distribution of ${ }^{137} \mathrm{Cs}$ in the seawater surface layer 1-30 years after the release into the ocean (from 2012 (upper left) to 2041 (lower right))

seawater (0-100 m) on April 1 since its release (2012-2041). The ${ }^{137}$ Cs released off the coast of Fukushima Prefecture moved eastward and was carried away by the Kuroshio Current. The part having the highest concentration in the entire ocean surface will reach the west coast of North America in 5 years (2016). Following the subsequent diffusion, the concentration in the entire North Pacific will become almost uniform in 20 years (2031) and will not show noticeable difference in concentration.

According to the slide published by IAEA on May 5, it was predicted that ${ }^{137} \mathrm{Cs}$ will reach North America in 1 to 2 years. However, according to LAMER, ${ }^{137} \mathrm{Cs}$ will take $3-5$ years to reach the west coast of North America because the apparent current is slow due to the smoothing of local currents by the horizontal resolution $\left(2^{\circ}\right)$ of the ocean general circulation model. Although there is a possibility that a part of the water mass that contains ${ }^{137} \mathrm{Cs}$ will reach the west coast of North America in $1-2$ years, most ${ }^{137} \mathrm{Cs}$ will require 3-5 years to reach there.

Figure 2 shows the yearly change of the highest concentration in the entire ocean since 2012. The highest concentration in the surface layer after 2012 was calculated to be $\sim 23$ $\mathrm{Bq} / \mathrm{m}^{3}$. In contrast, the average concentration of ${ }^{137} \mathrm{Cs}$ in the seawater originated from atmospheric nuclear tests collected off the coast of Fukushima Prefecture was $1.7 \mathrm{~Bq} / \mathrm{m}^{3}$ according to the significant 43 data obtained from the environmental radiation database ${ }^{6}$. Thus, the 


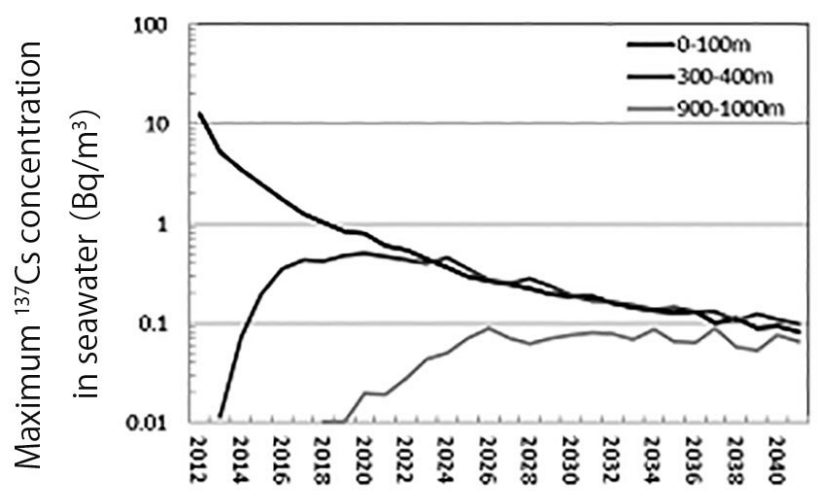

Figure 2 Chronological change of the highest concentration in the entire ocean

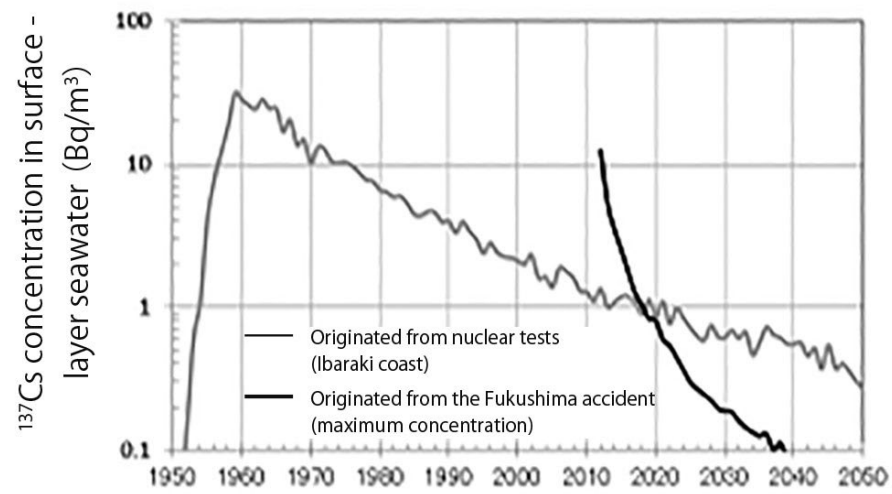

Figure 3 Comparison with the ${ }^{137} \mathrm{Cs}$ concentration in the surface of seawater originated from atmospheric nuclear tests

${ }^{137}$ Cs concentration from Fukushima as of April 2012 is $~ 14$ times that from the nuclear tests. Later, the highest concentration in the surface layer decreases. In 12 years (2023), the concentration will be $<1 \mathrm{~Bq} / \mathrm{m}^{3}$. At the same time, diffusion from the surface layer to the lower layers progresses. Therefore, the highest concentration of the layer at 300-400 m depth will slowly increase. Its concentration will be approximately similar to that of the surface layer in 10 years and then decrease, as was the case in the surface layer. At 900-1000 m, the concentration will slowly increase until 2026, and then change slightly. By 2041, after 30 years, all the highest concentrations from the surface layer to $1,000 \mathrm{~m}$ will be $\sim 0.2 \mathrm{~Bq} / \mathrm{m}^{3}$.

Figure 3 shows its comparison with the ${ }^{137} \mathrm{Cs}$ concentration calculation ${ }^{3)}$ in the seawater originated from atmospheric nuclear tests collected off the coast of Ibaraki. Although in $2012,{ }^{137} \mathrm{Cs}$ was $\sim 17$ times the concentration determined from the nuclear tests, it was about the same as the ${ }^{137} \mathrm{Cs}$ concentration determined from nuclear tests in around 1960 . The ${ }^{137} \mathrm{Cs}$ concentration from the accident decreases rapidly; it will decrease to about the same level by 2023 and to about half by 2031 .

Meanwhile, when the value obtained from dividing the input amount into the ocean $(\mathrm{Bq}$ input) by the highest concentration in the seawater $\left(\mathrm{Bq} / \mathrm{m}^{3}\right)$ is defined as the "minimum dilution rate," it becomes an index for indicating the minimum degree of dilution as it does not depend on the amount of release. Figure 4 shows the yearly change of the minimum dilution 
Table 5 Highest concentration in seawater of the entire ocean after one year

\begin{tabular}{lccc}
\hline & ${ }^{131} \mathrm{I}$ & ${ }^{134} \mathrm{Cs}$ & ${ }^{137} \mathrm{Cs}$ \\
\hline Maximum Concentration in Seawater $\left(\mathrm{Bq} / \mathrm{m}^{3}\right)$ & $4.7 \mathrm{E}-12$ & 20 & 23 \\
Concentration Limit of Water $\left(\mathrm{Bq} / \mathrm{m}^{3}\right)$ & 40000 & 60000 & 90000 \\
\hline
\end{tabular}

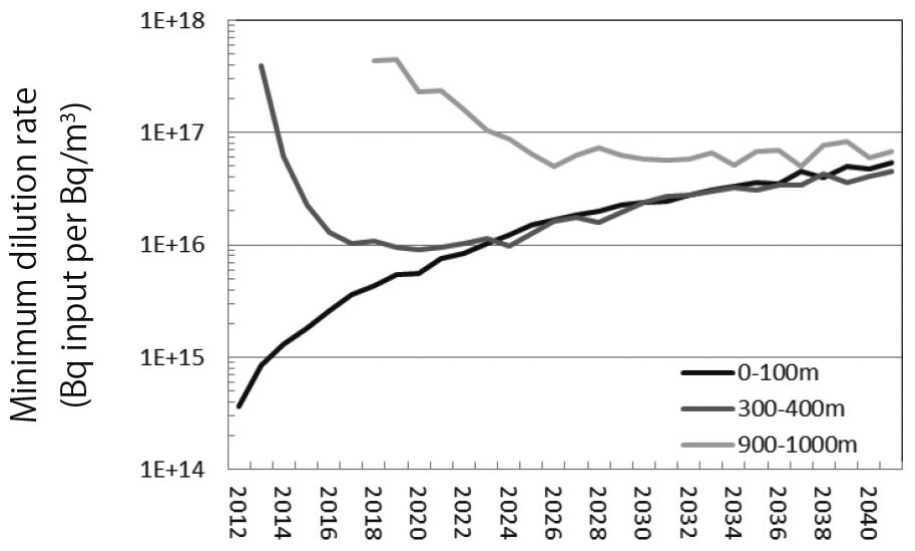

Figure 4 Chronological change of the minimum dilution rate in the entire ocean

rate. The minimum dilution rate in the surface layer is at its smallest level after one year at $\sim 3 \times 10^{14} \mathrm{~m}^{3}$. It continues to increase (dilute) after this point of time and becomes $\sim 5 \times 10^{16} \mathrm{~m}^{3}$ in 30 years. At deeper levels, ${ }^{137} \mathrm{Cs}$ initially has larger minimum dilution rate and it becomes approximately similar to that of the surface layer in 30 years.

The simulation result of the hypothetical release from Tokai reprocessing plant conducted in 2001 by Nakano et al. showed that when $6 \mathrm{TBq}$ of ${ }^{137} \mathrm{Cs}$, which is 100 times the yearly release limit of $55 \mathrm{GBq}$ stipulated in the reprocessing plants safety regulation, is hypothetically released, its maximum concentration is $<0.1 \mathrm{~Bq} / \mathrm{m}^{3}$ after one year. In this case, the minimum dilution rate is $>6 \times 10^{13} \mathrm{~m}^{3}$. The time was calculated by considering the horizontal diffusion coefficient obtained from literature, which was lower on the safety side than today $\left(2 \times 10^{3} \mathrm{~m}^{2} / \mathrm{s}\right)$; thus, its result was slightly smaller.

A realistic horizontal diffusion coefficient that matches the measurement was set later. ${ }^{3)}$ Then, release from Fukushima coast and Ibaraki coast after one year exhibit the minimum dilution rates. In other words, the highest concentration in relation to the unit release amount, displayed almost the same calculation result.

As discussed above, the highest concentration and the minimum dilution rate are numerical values taken from the place where the severest value in the world ocean is obtained at that time. Therefore, all other places have lower concentration and higher dilution rate. Table 5 shows the highest amount after one year obtained from the half-life adjustment of the calculation result of ${ }^{137} \mathrm{Cs}$ together with the concentration limit of water.

\section{(2) Internal Exposure Dose Caused by Seafood Ingestion}

Table 6 lists the internal exposure dose resulting from hypothetically eating only the seafood from the seawater that has the highest concentration of radioactive materials originated from Fukushima in the world (highest concentration shown in Table 5) for one year since April 2012. 
INSIGHTS CONCERNING THE FUKUSHIMA DAIICHI NUCLEAR ACCIDENT Vol. 1

Table 6 Internal exposure dose caused by seafood ingestion

\begin{tabular}{lcccc} 
& & & Unit: $\mu \mathrm{Sv} / \mathrm{y}$ \\
\hline Creature Type & ${ }^{131} \mathrm{I}$ & ${ }^{134} \mathrm{Cs}$ & ${ }^{137} \mathrm{Cs}$ & Total \\
\hline Fish & $2.1 \mathrm{E}-14$ & 0.89 & 0.70 & 1.6 \\
Crustacean & $6.1 \mathrm{E}-16$ & 0.037 & 0.030 & 0.067 \\
Cephalopod & $6.2 \mathrm{E}-16$ & 0.0069 & 0.0054 & 0.012 \\
Shellfish & $1.3 \mathrm{E}-15$ & 0.029 & 0.023 & 0.052 \\
Seaweed & $3.7 \mathrm{E}-12$ & 0.069 & 0.055 & 0.12 \\
\hline Total & $3.8 \mathrm{E}-12$ & 1.0 & 0.82 & 1.8 \\
\hline
\end{tabular}

The internal exposure dose of the sum of all seafood is $3.8 \times 10^{-12}, 1.0$, and $0.82 \mu \mathrm{Sv}$ for ${ }^{131} \mathrm{I},{ }^{134} \mathrm{Cs}$, and ${ }^{137} \mathrm{Cs}$, respectively, and the total exposure dose was $1.8 \mu \mathrm{Sv}$. Considering the average internal exposure dose among Japanese caused by seafood ingestion originated from atmospheric nuclear tests was $\sim 1.7 \mu \mathrm{Sv} / \mathrm{y}$ between 1963 and 1973 when it was the highest ${ }^{8)}$, the hypothetical released amount of this incident will cause about the same amount of internal exposure caused by atmospheric nuclear tests even at its highest estimation.

\section{Conclusions}

Ocean dispersion calculations on radioactivity released from Fukushima Daiichi Nuclear Power Plant using LAMER was conducted to predict the wide-area concentration distribution after one year until 2041, which is 30 years after the accident. Moreover, the internal exposure dose caused by seafood ingestion was estimated. Note that the concentrations of the coastal area during the first year from the accident were outside the applicability of LAMER.

When we postulate that $8.45 \mathrm{PBq}$ of ${ }^{137} \mathrm{Cs}$ have been released, it is calculated that the ${ }^{137} \mathrm{Cs}$ concentration in seawater after April 2012 will be highest $23 \mathrm{~Bq} / \mathrm{m}^{3}$, which is $\sim 14$ times the concentration in seawater originated from the atmospheric nuclear tests. This is however about the same concentration as the time around 1960. Later, the highest concentration continues to decrease and by 2023 , it will be about the same level as the concentration derived from the nuclear tests $\left(<1 \mathrm{~Bq} / \mathrm{m}^{3}\right)$.

Meanwhile, the internal exposure from ${ }^{131} \mathrm{I},{ }^{134} \mathrm{Cs}$, and ${ }^{137} \mathrm{Cs}$ due to seafood ingestion was calculated to be maximum at $1.8 \mu \mathrm{Sv} / \mathrm{y}$ after April 2012, which is about the same as the past dose from seafood ingestion derived from the atmospheric nuclear tests.

When the spatial and chronological distributions of the release input into the ocean are determined in the future, detailed evaluations of the radioactive nuclides concentration in the seawater and the dose of internal exposure caused by seafood ingestion will be possible. This may contribute to the future safety validation of marine products. In addition, estimating the released amount by reverse calculation using the measured concentration in seawater is possible to a certain extent via this simulation.

\section{References}

1) Nakano M. LAMER: Long-term Assessment Model for Radioactivity in the oceans. JAEA-Data/ Code 2007-024.2008. [in Japanese]

2) IAEA. Sediment distribution coefficients and concentration factors for biota in the marine environment. Technical Report Series. 2004; 422.

3) Nakano M. Long-term assessment model of radionuclides in the oceans (LAMER). Development 
and validation of the diffusion model in global oceans. Saikuru Kiko Giho (JNC Tech. Rpt.). 2004; 22:67-76. [in Japanese]

4) UNSCEAR, Annex C. Exposures to the public from man-made sources of radiation. Sources and Effects of Ionizing Radiation. 2000; 158.

5) Ministry of Health, Labor and Welfare. Report on study of the health/nutrition of the population, http://www.mhlw.go.jp/bunya/kenkou/eiyou/h20-houkoku.html. 2011 April. [in Japanese]

6) Ministry of Education, Culture, Sports, Science and Technology. Environmental Radiation Database, http://search.kankyo-hoshano.go.jp/. 2011 April. [in Japanese]

7) Nakano M. Radioactive Materials Movement Model for the Global Scale Marine Environment. Saikuru Kiko Giho (JNC Tech. Rpt.). 2001; 11. [In Japanese]

8) Nakano M. Calculation of Effective Dose Originated from Atmospheric Nuclear Tests through Seafood Ingestion. (Jpn. J. Health Phys.) 2007; 42:329-341. [in Japanese] 